\title{
Intestinal circulation, oxygenation and metabolism is not affected by oleic acid lung injury
}

Jonas Claesson ${ }^{1}$, Stefan Lehtipalo ${ }^{1}$, Ulf Bergstrand ${ }^{1}$, Conny Arnerlöv ${ }^{2}$, David Rocksen ${ }^{3}$, Magnus Hultin ${ }^{1}$ and Ola Winsö ${ }^{1}$

Departments of ${ }^{1}$ Surgical and Perioperative Sciences, Anesthesiology and Intensive Care and ${ }^{2}$ Surgery, Umeå University Hospital, Umeå, and ${ }^{3}$ Department of Medical Countermeasures, Swedish Defence Research Agency, Umeå, Sweden

\section{Summary}

\section{Correspondence}

Jonas Claesson, MD, Department of Surgical and Perioperative Sciences, Anesthesiology and Intensive Care, Umeå University Hospital, SE-901 85 Umeå, Sweden

E-mail: jonas.claesson@vvll.se

\section{Accepted for publication}

Received 13 May 2005;

accepted 26 August 2005

\section{Key words}

acute respiratory distress syndrome; mesenteric oxygen delivery; mesenteric oxygen uptake;

mesenteric tissue oxygenation; splanchnic circulation; swine
This study was performed to establish a platform for further studies on effects of ventilatory treatment modalities on the intestines during mechanical ventilation of acute lung injury (ALI). We tested the hypotheses that oleic acid (OA) infusion causes changes in intestinal circulation, oxygenation and metabolism, and that $\mathrm{OA}$ is distributed to tissues outside the lung. This was performed as an experimental, prospective and controlled study in an university animal research laboratory. Thirteen juvenile anaesthetized pigs were used in the main study, where seven were given an intravenous infusion of $0 \cdot 1 \mathrm{ml} \mathrm{kg}{ }^{-1} \mathrm{OA}$ and six served as control (surgery only). In a separate study, four animals were given an intravenous infusion of $0 \cdot 1 \mathrm{ml} \mathrm{kg}^{-1}$ ${ }^{3} \mathrm{H}$-labelled OA. We measured systemic and mesenteric (portal venous blood flow, jejunal mucosal perfusion) haemodynamic parameters, mesenteric oxygenation (jejunal tissue oxygen tension) and systemic cytokines (tumour necrosis factor- $\alpha$ and interleukin-6). We calculated mesenteric lactate flux and mesenteric oxygen delivery, uptake and extraction ratio. In the animals given ${ }^{3} \mathrm{H}-\mathrm{OA}$, we measured ${ }^{3} \mathrm{H}-\mathrm{OA}$ in different tissues (lungs, heart, liver, kidney, stomach, jejunum, colon and arterial blood). We found that OA given intravenously is distributed in small amounts to the intestines. This intestinal exposure to OA does not cause intestinal injury when evaluating mesenteric blood flow, metabolism or oxygenation. OA infusion induced a moderate increase in mean pulmonary arterial pressure and a decrease in $\mathrm{PaO}_{2} /$ Fraction inspired $\mathrm{O}_{2}(\mathrm{P} / \mathrm{F})$ ratio, giving evidence of severe lung injury. Consequently, the OA lung injury model is suitable for studies on intestinal effects of ventilatory treatment modalities during mechanical ventilation of ALI.

\section{Introduction}

The intestine, suggested to be a key organ in the development of multiple organ failure (Mainous et al., 1995; Gullo \& Berlot, 1996; Nieuwenhuijzen \& Goris, 1999), is well known to be negatively affected by ventilator treatment both in healthy and injured lungs (Winso et al., 1986; Claesson et al., 2003; Guery et al., 2003; Imai et al., 2003; Lehtipalo et al., 2003; Plotz et al., 2004). Research from our own group has shown that treatment with positive end-expiratory pressure (PEEP) reduces portal blood flow during general surgery in man (Winso et al., 1986). Further, we have shown that, in a porcine model, treatment with modest levels of PEEP causes ischaemia when intestinal perfusion pressure is reduced (Lehtipalo et al., 2003). We have also shown that lung recruitment manoeuvres in patients with acute lung injury (ALI) decreases gastric mucosal blood flow (Claesson et al.,
2003). Also, in lung injury, the resulting general hypoxia may cause redistribution of regional perfusion, disfavouring splanchnic oxygen delivery.

Others have shown (Plotz et al., 2004) that the intestines might be affected negatively by several other mechanisms during mechanical ventilation. Systemically released cytokines and apoptotic mediators from the lung might cause increased intestinal permeability and intestinal epithelial apoptosis promoting bacterial translocation (Guery et al., 2003; Imai et al., 2003). From this review, it is obvious that many factors affect the intestines during mechanical ventilation and that the interactions between these factors are complex. It is important to elucidate these interactions as there are experimental evidence gathering that there might be clinically relevant interactions between mechanical ventilation in lung injury, changes in intestinal permeability and subsequent development of multiple organ failure (Doig et al., 1998; Dreyfuss \& Saumon, 1998). 
The main purpose of this study was to establish a platform for further studies on effects of different ventilatory treatment modalities on the intestines during mechanical ventilation of ALI. The oleic acid (OA) lung injury model is one of the accepted standards to study ventilatory management in ALI (Kloot et al., 2000; Neumann \& Hedenstierna, 2001; Pelosi et al., 2001; Lim et al., 2004).

However, it remains unclear if OA is solely distributed to the lung, or whether it also can be found in other organs. If the latter were the case, possible local effect such as inflammatory reaction, and further regional changes in organ perfusion and metabolism might occur. This in turn might result in direct impairment of organ function other than in the lung alone. Finally, only scarce data exist, documenting stability of the OA model for several hours.

First, in the main study, we aimed to test the hypothesis that OA infusion has intrinsic effects on intestinal circulation, metabolism and oxygenation. Further, in a separate study, we aimed to test the hypothesis that infused OA would be distributed to tissues outside the lung. To this end, we used an established experimental model of OA-induced ALI.

\section{Methods}

The study was approved by the University Animal Experiment Ethics Committee. Thirteen female juvenile pigs, with a mean weight of $30 \cdot 8 \pm 1 \cdot 1 \mathrm{~kg}$, were used in the main study. Another four pigs, with a mean weight of $27 \cdot 7 \pm 0 \cdot 8 \mathrm{~kg}$, were used in a separate study of tissue distribution of tritium $\left({ }^{3} \mathrm{H}\right)$-labelled OA. All procedures were carried out according to the guidelines of the National Institute of Health Guide for the care and use of laboratory animals (7th edn, 1996).

\section{Anaesthesia}

Animals were fasted overnight with free access to water. After premedication with ketamine, azaperon and atropine i.m., anaesthesia was induced by sodium pentobarbital $\left(10 \mathrm{mg} \mathrm{kg}^{-1}\right.$, i.v.) followed by continuous infusions of sodium pentobarbital 4-6 $\mathrm{mg} \mathrm{kg}^{-1} \mathrm{~h}^{-1}$ i.v., midazolam $0.3 \mathrm{mg} \mathrm{kg}^{-1} \mathrm{~h}^{-1}$ i.v. and fentanyl $20 \mu \mathrm{g} \mathrm{kg}^{-1} \mathrm{~h}^{-1}$ i.v. No muscle relaxants were used. After tracheostomy, mechanical ventilation with oxygen in air $\left(\begin{array}{ll}30 \% & \mathrm{O}_{2}\end{array}\right)$ was performed using pressure-regulated volume control (Evita 4, Dräger, Germany), tidal volume of $10 \mathrm{ml} \mathrm{kg}^{-1}$ and frequency of $20-30 \mathrm{~b} \mathrm{~min}^{-1}$. Ventilation was adjusted to normocapnia as judged by end-tidal $\mathrm{CO}_{2}$ levels (Artema; Artema Medical AB, Sundbyberg, Sweden) and arterial blood gas analyses (ABL-5 autoanalyser; Radiometer, Copenhagen, Denmark). Blood samples for lactate concentration were analysed by an automated analyser (YSI Sport 2300 Stat Plus; Yellow Springs Instruments, Inc., Yellow Springs, Ohio, USA). All animals received i.v. infusions of Ringer's acetate $10 \mathrm{ml} \mathrm{kg}^{-1} \mathrm{~h}^{-1}$ and hydroxyaethylstarch 200/0.6 (Voluven, Fresenius Kabi, Sweden) $2 \mathrm{ml} \mathrm{kg}^{-1} \mathrm{~h}^{-1}$, with additional boluses given to keep central venous pressure (CVP) in the range of $5-7 \mathrm{mmHg}$ during the experiment. Core temperature was kept between 37 and $39^{\circ} \mathrm{C}$ using heating blankets.

\section{Instrumentation and measurements}

Instrumentation of the animals was performed as previously described regarding intravascular catheters, portal blood flow $\left(\mathrm{Q}_{\text {PORT }}\right)$, partial tissue $\mathrm{O}_{2}$ pressure $\left(\mathrm{PtiO}_{2}\right)$ and jejunal mucosal perfusion (JMP) measurements (Lehtipalo et al., 2003). In eight pigs a catheter (Pulsiocath 4F; Pulsion Medical Systems AG, Munich, Germany) was inserted via a branch of the left carotid artery for monitoring of pulse contour cardiac output (CO). The pulse contour computer continuously calculated the arterial pulse contour CO. Calibration of the system was performed twice during the experiment according to the manufacturer's instructions by determination of the arterial thermodilution $\mathrm{CO}$, using three to four injections of $20 \mathrm{ml}$ iced 0.9\% saline (Sakka et al., 1999). In those pigs where continuous CO monitoring was not available, CO was measured using the pulmonary artery catheter. Thermodilution $\mathrm{CO}$ data $(5 \mathrm{ml}$ of iced $0.9 \% \mathrm{NaCl}$ as indicator) are presented as means of three consecutive measurements within 2 min, not differing more than $10 \%$. Splenectomy was performed in all animals to eliminate dilution of portal venous blood. All pressure transducers (System DPT6000 , PvB; Triplus, Kungsbacka, Sweden) were calibrated to atmospheric pressure at the level of the right atrium by a saline column. Continuous data were acquired with Acknowledge ${ }^{\circledR}$ III (Biopac Systems Inc., Goleta, California, USA) as previously described (Lehtipalo et al., 2003).

\section{Cytokine measurements}

Arterial blood was centrifuged at $4^{\circ} \mathrm{C}$ at $915 \mathrm{~g}$ for $20 \mathrm{~min}$ and serum was collected after centrifugation. The serum samples were then frozen at $-70^{\circ} \mathrm{C}$ awaiting analysis. Cytokine ELISA kits for tumour necrosis factor (TNF)- $\alpha$ and interleukin (IL)- 6 were purchased from R\&D Systems Europe Ltd (Abingdon, UK). Assays were performed as recommended by the manufacturer with some minor modifications. Briefly, capture antibodies were incubated in microtitre 96-well ELISA plates (Nunc-Immuno Plate with Max Sorb surface, Tamro MedLab AB, Mölndal, Sweden) over night at room temperature. Plates were then washed (0.05\% Tween in physiologically buffered saline) and non-specific binding sites in each well were blocked by incubating with a buffer consisting of bovine serum albumin $(1 \%)$ and sucrose $(5 \%)$ in physiologically buffered saline. One hour later, $100 \mu \mathrm{l}$ of each serum sample was added to the wells. Serial dilutions of serum samples were performed in order to keep optical density values within the linear range of the twofold serial dilution standard curve. Final analysis was performed with serum dilutions 1:10. After $2 \mathrm{~h}$ incubation, bound cytokines were detected using a biotin-coupled detection antibody which was quantified using a strepavidin-peroxidase conjugate. After repeated washing, a ready-to-use peroxidase substrate with $3,3^{\prime}, 5,5^{\prime}$-tetramethylbenzidine and hydrogen peroxide (Sigma- 
Aldrich, Stockholm, Sweden) was used. The plates were then incubated at room temperature, allowing the reaction to proceed to the desired extinction. The reaction was terminated by adding $50 \mu \mathrm{l}$ of $1 \mathrm{M} \mathrm{H}_{2} \mathrm{SO}_{4}$ to each well. The soluble product was read at $450 \mathrm{~nm}$ in a Labsystems iEMS ELISA reader.

\section{Determination of tissue ${ }^{3} \mathrm{H}$ oleic acid radioactivity}

The individual organs were harvested and placed in a sink, and blood was allowed to drain freely. Thereafter, three 1-g tissue samples from each organ (heart, lungs, liver, kidneys, stomach, jejunum and colon) were separately homogenized with a tissue homogenisator (Polytron; Kinematica, Basel, Switzerland) and extracted in $30 \mathrm{ml}$ chloroform-methanol 2:1 per gram and then left overnight. One millilitre of arterial blood was also sampled and treated accordingly. An aliquot of the extract was centrifuged for $10 \mathrm{~min}$ to remove tissue residues. Three millilitre of the clear phase was added to $1.2 \mathrm{ml} 0.1 \mathrm{M} \mathrm{HCl}$ and shaken. After an additional centrifugation to separate the two phases, the upper phase and protein layer were discarded, and $1 \mathrm{ml}$ of the lower phase was transferred to a scintillation vial. After the chloroform was evaporated over night, scintillation fluid (OptiPhase HiSafe III; Perkin-Elmer, Stockholm, Sweden) was added and allowed to mix for another $24 \mathrm{~h}$, after which the sample activity was counted in a Wallace 1414 Winspectral $\beta$-counter. Estimation of the contribution of ${ }^{3} \mathrm{H}-\mathrm{OA}$ radioactivity from residual blood was performed based on previously reported individual organ residual blood volume (Hansard, 1956).

\section{Experimental protocol, main study}

After completed instrumentation, a stabilization period of 60 min was allowed to elapse. The animals were divided into two groups, a control group $(\mathrm{n}=6)$ and an OA group $(\mathrm{n}=7)$. In the OA group, lung injury was established by a slow 30-min intravenous infusion of $0.1 \mathrm{ml} \mathrm{kg}{ }^{-1} \mathrm{OA}$ (Apoteksbolaget, Göteborg, Sweden) suspended in $20 \mathrm{ml}$ saline via the central venous catheter. Inspired oxygen concentration was adjusted between a $\mathrm{FiO}_{2}$ of 0.3 to 1.0 to maintain oxygen saturation above $92 \%$. During the OA infusion ventilation was increased when needed to maintain normoventilation. Blood pressure was stabilized with additional colloid infusion (500-1000 ml to maintain CVP at 5-7 $\mathrm{mmHg}$ ) and repeated doses of adrenaline 5-20 $\mathrm{g}$ (to a total of $100-250 \mu \mathrm{g}$ ). After the 30-min OA infusion, PEEP $5 \mathrm{~cm} \mathrm{H}_{2} \mathrm{O}$ was added and the animals were allowed to recover for $80 \mathrm{~min}$.

In the control group only PEEP $5 \mathrm{~cm} \mathrm{H}_{2} \mathrm{O}$ was added after $30 \mathrm{~min}$. No extra fluids or adrenaline was given. In both groups, data sets were recorded at time zero and 120, 150, 175, 200 and $240 \mathrm{~min}$ after time zero.

Recordings included heart rate (HR), mean arterial pressure (MAP), CVP, mean pulmonary arterial pressure (MPAP), CO, $\mathrm{Q}_{\mathrm{PORT}}$, portal venous pressure $\left(\mathrm{P}_{\mathrm{PORT}}\right), \mathrm{PtiO}_{2}$ and JMP. Blood samples for blood gas analyses and oxygen saturation measure- ments were drawn from aortic and portal venous catheters in conjunction with the haemodynamic recordings. At time zero, 120 and 240 min thereafter mixed venous blood samples for blood gas analyses were collected, venous admixture (Qs/Qt) was calculated and cytokines were measured. Animals were killed with an intravenous infusion of $\mathrm{KCl}$ under deep barbiturate anaesthesia at the end of the experiment.

\section{Experimental protocol, ${ }^{3} \mathrm{H}-\mathrm{OA}$ distribution}

In a separate group of four animals, the distribution of OA to different tissues was studied. These animals were anaesthetized and instrumented as described above, with the exception that the only intra-abdominal instrumentation performed was splenectomy.

After completed instrumentation the animals were allowed to stabilize for $30 \mathrm{~min} .{ }^{3} \mathrm{H}$-labelled OA $0 \cdot 1 \mathrm{ml} \mathrm{kg}{ }^{-1}(200 \mu \mathrm{Ci})$ was then injected as a slow i.v. infusion during $30 \mathrm{~min}$ in the central venous catheter as described above. The animals received the same treatment regarding ventilation, fluids and adrenaline as the animals in the OA group in the main study. The animals were followed for another $45 \mathrm{~min}$ after the OA infusion. In this distribution study, HR, MAP, CVP and MPAP were continuously recorded. Arterial and mixed venous blood gases were sampled at 15 min intervals. All animals were killed with an intravenous infusion of $\mathrm{KCl}$ under deep barbiturate anaesthesia at the end the experiment. After death, tissue samples (three 1-g samples from each tissue) and $1 \mathrm{ml}$ arterial blood were taken for determination of ${ }^{3} \mathrm{H}$-labelled OA radioactivity.

\section{Statistics}

All values are given as mean \pm SEM. Comparisons were made between groups at time-points zero, 120 and $240 \mathrm{~min}$. Comparisons were made within groups between time-point zero and $120 \mathrm{~min}$ and between 120 and $240 \mathrm{~min}$. For comparisons between groups an independent samples t-test was used. For comparisons within groups a paired samples t-test was used. A $P<0.05$ was considered significant for all tests. The statistical analysis was performed with the SPSS software package (version 11.5; SPSS Inc., Chicago IL, USA).

\section{Results, main study}

The results are reported as changes occurring during the first $120 \mathrm{~min}$ after time zero (acute phase) followed by changes occurring between 120 and $240 \mathrm{~min}$ after time zero (late phase). At time zero there were no significant differences between groups apart from slightly higher $\mathrm{pH}$ in the OA group.

\section{Acute phase, changes within groups}

In the control group MAP and $\mathrm{Q}_{\mathrm{PORT}}$ decreased (QPORT from $1059 \pm 153$ to $800 \pm 103 \mathrm{ml} \mathrm{min}^{-1}$ ). CO decreased although not significantly (Table 1, Fig. 1). Mesenteric oxygen delivery 
Table 1 Circulatory and respiratory parameters.

\begin{tabular}{lccc}
\hline & Time zero & 120 min & 240 min \\
\hline $\mathrm{MAP}(\mathrm{mmHg})$ & & & \\
OA & $98 \pm 4$ & $85 \pm 4^{*}$ & $80 \pm 4^{\#}$ \\
Control & $92 \pm 2$ & $82 \pm 4^{*}$ & $80 \pm 3$ \\
$\mathrm{CVP}(\mathrm{mmHg})$ & & & \\
OA & $6 \pm 0$ & $8 \pm 0$ & $6 \pm 0^{\#}$ \\
Control & $6 \pm 0$ & $7 \pm 1$ & $8 \pm 1$ \\
$\mathrm{MPAP}(\mathrm{mmHg})$ & & & \\
OA & $22 \pm 1$ & $37 \pm 2 * \S$ & $30 \pm 2^{\#}$ \\
Control & $23 \pm 1$ & $22 \pm 1$ & $25 \pm 3$ \\
$\mathrm{CO}\left(\mathrm{L} \mathrm{min}{ }^{-1}\right)$ & & & \\
OA & $4 \cdot 8 \pm 0 \cdot 3$ & $3 \cdot 8 \pm 0 \cdot 2 *$ & $3 \cdot 7 \pm 0 \cdot 2$ \\
Control & $4 \cdot 7 \pm 0 \cdot 5$ & $3 \cdot 5 \pm 0 \cdot 3$ & $3 \cdot 5 \pm 0 \cdot 1$ \\
$\mathrm{PH}$ & & & \\
OA & $7 \cdot 54 \pm 0 \cdot 01^{\S}$ & $7 \cdot 40 \pm 0 \cdot 02^{*}$ & $7.44 \pm 0 \cdot 04$ \\
Control & $7 \cdot 48 \pm 0 \cdot 01$ & $7 \cdot 48 \pm 0 \cdot 01$ & $7 \cdot 47 \pm 0 \cdot 01$ \\
$\mathrm{PaCO}(\mathrm{kPa})$ & & & \\
OA & $4 \cdot 5 \pm 0 \cdot 3$ & $5 \cdot 9 \pm 0 \cdot 3 *$ & $5 \cdot 6 \pm 0 \cdot 7$ \\
Control & $5 \cdot 0 \pm 0 \cdot 1$ & $4 \cdot 9 \pm 0 \cdot 1$ & $5 \cdot 0 \pm 0 \cdot 2$ \\
$\mathrm{PaO}(\mathrm{kPa})$ & & & \\
OA & $15 \cdot 2 \pm 0 \cdot 9$ & $15 \cdot 7 \pm 2 \cdot 0$ & $15 \cdot 0 \pm 2 \cdot 1$ \\
Control & $14 \cdot 5 \pm 0 \cdot 5$ & $15 \cdot 4 \pm 0 \cdot 4$ & $13 \cdot 8 \pm 0 \cdot 8^{\#}$ \\
$\mathrm{P} / \mathrm{F}(\mathrm{kPa})$ & & & \\
OA & $49 \cdot 2 \pm 4 \cdot 0$ & $27 \cdot 6 \pm 4 \cdot 8 * \S$ & $25 \cdot 9 \pm 4 \cdot 2^{\S}$ \\
Control & $48 \cdot 3 \pm 1 \cdot 5$ & $51 \cdot 3 \pm 1 \cdot 4$ & $46 \cdot 2 \pm 2 \cdot 6^{\#}$ \\
$\mathrm{Qs} / \mathrm{Qt}(\%)$ & & & \\
OA & $12 \pm 2$ & $22 \pm 5^{\S}$ & $21 \pm 5^{\S}$ \\
Control & $10 \pm 2$ & $7 \pm 1$ & $8 \pm 1$ \\
\hline
\end{tabular}

Data are presented as mean \pm SEM.

*Denotes a significant difference $(p<0.05)$ time zero versus $120 \mathrm{~min}$.

\#Denotes a significant difference $(p<0 \cdot 05)$ at $120 \mathrm{~min}$ versus $240 \mathrm{~min}$ within groups.

${ }^{\S}$ Denotes significant difference $(p<0 \cdot 05)$ between groups.

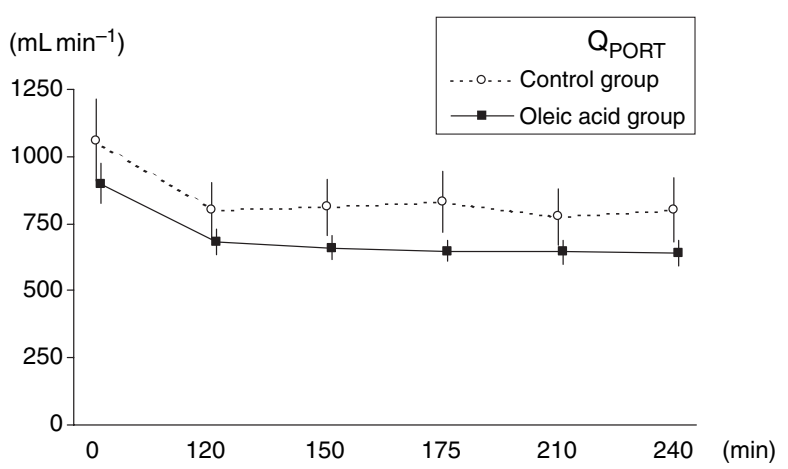

Figure 1 Q $\mathrm{Q}_{\text {PORT }}$ (portal venous blood flow). Values presented as mean \pm SEM (bars). For statistical comparisons see text.

$\left(\mathrm{M}-\mathrm{DO}_{2}\right)$ decreased from $132 \pm 18$ to $104 \pm 14 \mathrm{ml} \mathrm{min}^{-1}$ while mesenteric oxygen extraction ratio $\left(\mathrm{MO}_{2}\right.$-ER) increased from $21 \pm 3 \%$ to $28 \pm 3 \%$.

In the OA group MAP, $\mathrm{CO}, \mathrm{Q}_{\mathrm{PORT}}, \mathrm{pH}$ and $\mathrm{P} / \mathrm{F}$ ratio decreased ( $\mathrm{Q}_{\mathrm{PORT}}$ from $900 \pm 75$ to $681 \pm 47 \mathrm{ml} \mathrm{min}^{-1}$ ) while MPAP and $\mathrm{PaCO}_{2}$ increased (Table 1, Fig. 1). $\mathrm{M}-\mathrm{DO}_{2}$ decreased from $110 \pm 11$ to $82 \pm 7 \mathrm{ml} \mathrm{min}^{-1}$ while $\mathrm{MO}_{2}$-ER increased from $25 \pm 2 \%$ to $36 \pm 1 \%$.

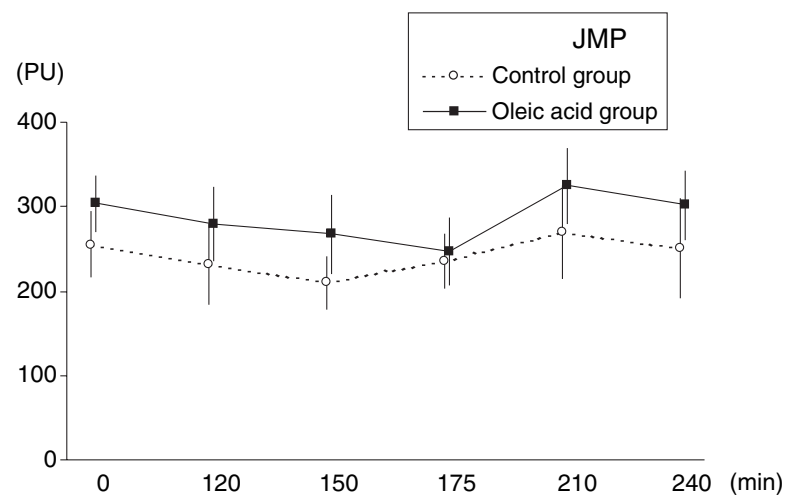

Figure 2 JMP (jejunal mucosal perfusion), perfusion units (PU). Values presented as mean \pm SEM (bars). For statistical comparisons see text.

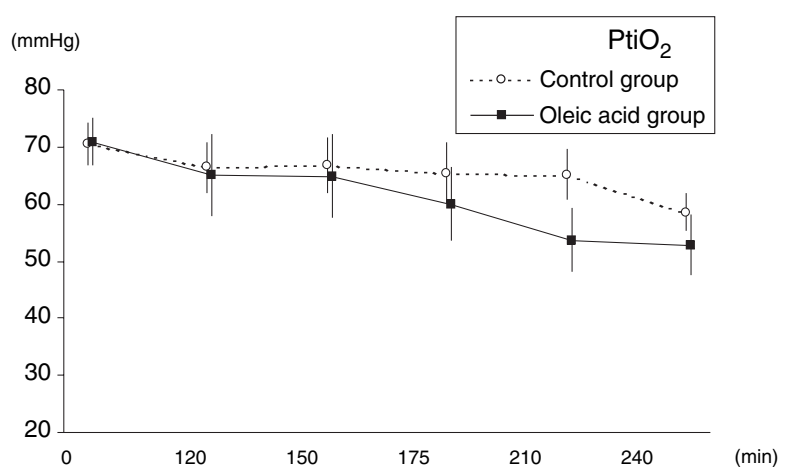

Figure $3 \mathrm{PtiO}_{2}$ (jejunal tissue oxygen tension). Values presented as mean \pm SEM (bars). For statistical comparisons see text.

\section{Acute phase, changes between groups}

Mean pulmonary arterial pressure, Qs/Qt and $\mathrm{MO}_{2}$-ER were higher in the $\mathrm{OA}$ group $\left(\mathrm{MO}_{2}\right.$-ER $36 \pm 1 \%$ and $28 \pm 3 \%$ respectively), while $\mathrm{pH}$ and $\mathrm{P} / \mathrm{F}$ ratio were lower in the $\mathrm{OA}$ group at $120 \mathrm{~min}$ after time zero (Table 1). Lactate flux decreased non-significantly within the OA group but was significantly lower than in the control group at 120 min after time zero (Fig. 4).

There were no significant changes in mesenteric oxygen uptake $\left(\mathrm{M}-\mathrm{VO}_{2}\right)$ (data not shown), JMP or $\mathrm{PtiO}_{2}$ within groups or between groups during the acute phase (Figs 2 and 3).

\section{Late phase, changes within groups}

In the OA group conditions were stable, with only slight but statistically significant decreases in MAP, CVP and MPAP (Table 1). $\mathrm{M}-\mathrm{DO}_{2}$ decreased from $82 \pm 7$ to $73 \pm 6 \mathrm{ml} \mathrm{min}{ }^{-1}$ while $\mathrm{MO}_{2}$-ER increased (from $36 \pm 1 \%$ to $42 \pm 2 \%$ ) resulting in unchanged $\mathrm{M}-\mathrm{VO}_{2}$.

In the control group there were small but significant decreases in $\mathrm{PaO}_{2}, \mathrm{P} / \mathrm{F}$ ratio and $\mathrm{PtiO}_{2} \quad\left(\mathrm{PtiO}_{2}\right.$ from $66 \pm 4$ to $58 \pm 3 \mathrm{mmHg}$ ) (Table 1, Fig. 3). 


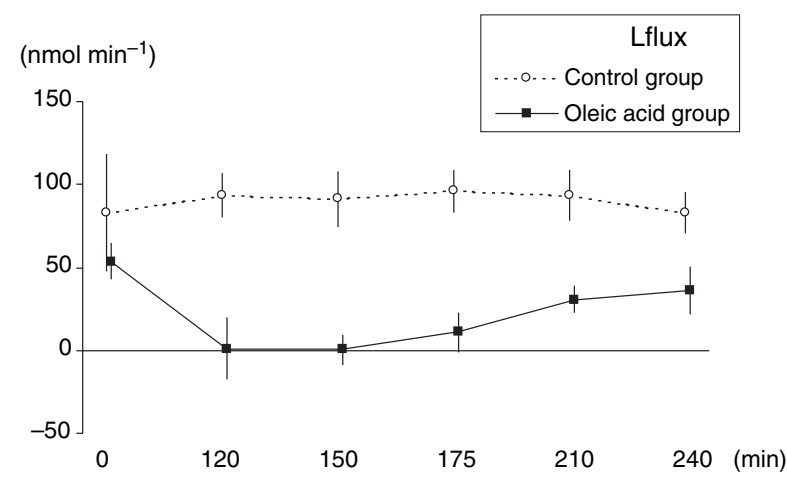

Figure $4 \mathrm{Lflx}$ (mesenteric net lactate flux). Values presented as mean \pm SEM (bars). For statistical comparisons see text.

\section{Late phase, changes between groups}

Lflx (mesenteric net lactate flux) and P/F ratio were lower in the OA group, while Qs/Qt and $\mathrm{MO}_{2}$-ER were higher in the OA group $\left(\mathrm{MO}_{2}\right.$-ER $42 \pm 2 \%$ versus $29 \pm 4 \%$ respectively) when comparing groups at $240 \mathrm{~min}$ after time zero (Table 1, Fig. 4). There were no significant differences between groups when comparing MAP, CVP, CO, Q QPORT, $\mathrm{M}-\mathrm{DO}_{2}, \mathrm{M}-\mathrm{VO}_{2}, \mathrm{JMP}$ or $\mathrm{PtiO}_{2}$ at $240 \mathrm{~min}$ after time zero.

\section{Systemic inflammation}

Systemic cytokines were measured in five animals in the OA group and six animals in the control group. TNF- $\alpha$ was not detected at any time in any animal. In one animal in each group, IL-6 was not detected at any time. Mean IL-6 levels in OA group were $104 \pm 73,186 \pm 61$ and $47 \pm 27 \mathrm{pg} \mathrm{ml}^{-1}$ at 0,120 and $240 \mathrm{~min}$ respectively and $296 \pm 245,408 \pm 240$ and $398 \pm$ $151 \mathrm{pg} \mathrm{ml}^{-1}$ in the control group at 0,120 and $240 \mathrm{~min}$ respectively. Cytokine levels were very low in all groups, and there were no significant differences between groups.

\section{Results, ${ }^{3} \mathrm{H}-\mathrm{OA}$ distribution study}

Haemodynamic and respiratory data (data not shown) were similar to data obtained in the OA group in the main study. Approximately $30 \%$ of the injected dose were recovered in the studied organs (lungs 16.6 $\pm 3 \cdot 4 \%$, heart $1 \cdot 1 \pm 0 \cdot 3 \%$, liver $9 \cdot 0 \pm$ $0 \cdot 5 \%$, kidneys $0 \cdot 7 \pm 0 \cdot 1 \%$, stomach $0 \cdot 3 \pm 0 \cdot 1 \%$, jejunum $1 \cdot 0 \pm 0 \cdot 3$, colon $0 \cdot 4 \pm 0 \cdot 1 \%$ and arterial blood $1 \cdot 5 \pm 0 \cdot 4 \%$.

\section{Discussion}

The OA lung injury model is an established and previously welldescribed model, where the intestinal effects has not been clearly elucidated. The OA infusion induces a moderate to severe lung injury with hypoxemia, pulmonary capillary leakage and mechanical properties similar to those found in patients with moderate to severe ARDS (Rosenthal et al., 1998). The OA lung injury is caused both by a direct injury to the pulmonary capillary endothelium and occlusive microthrombosis (Baker et al., 1969; Derks \& Jacobovitz-Derks, 1977; Grotjohan et al., 1993). It is generally considered a local lung injury model, but we have demonstrated that OA can be found in many extrapulmonary tissues 45 min after completed OA infusion. We could recover approximately $30 \%$ of the administered dose of ${ }^{3} \mathrm{H}$-labelled OA. The remainder was either distributed to large tissues not studied (mainly fat and muscle tissue) or already metabolized to water (Goeransson \& Olivecrona, 1965). When determining ${ }^{3} \mathrm{H}-\mathrm{OA}$ tissue radioactivity, the contribution of residual blood ${ }^{3} \mathrm{H}-\mathrm{OA}$ radioactivity in the organ has to be accounted for. Using previously published data on organ residual blood volume (Hansard, 1956), we calculated corrections for each organ (data not presented), and the contribution of residual blood ${ }^{3} \mathrm{H}-\mathrm{OA}$ radioactivity was judged to be negligible. A small amount of ${ }^{3} \mathrm{H}$-labelled OA was recovered from the intestine, a total of $2 \%$ of the given dose (equal to $5 \%$ of the recovered dose). This shows that the intestines during OA infusion are exposed to a potentially inflammatory stimulus.

We measured systemic levels of the proinflammatory cytokines TNF- $\alpha$ and IL- 6 . TNF- $\alpha$ was not detected in any animal at any time, while IL-6 levels were generally low in both groups (in the observed range small variations in optical densities gives large variations in measured values). This finding suggests that OA infusion does not cause general systemic inflammation, but does not rule out the possibility of a local inflammatory reaction in the intestines.

When evaluating local blood flow, metabolism or oxygenation we found no indications of intestinal injury. There were no indications of intestinal hypoperfusion in either of the two groups. Mesenteric oxygen delivery and extraction ratio levels in both groups were in line with previously reported values not associated with intestinal ischaemia (Lehtipalo et al., 2001). As shown in Fig. 3, jejunal tissue oxygen tension decreased in the OA group, but only to a minor degree, and to absolute levels above ischaemic threshold values of $45 \mathrm{mmHg}$ (Lehtipalo et al., 2003).

In the control group there was a constant and small net lactate production, without any signs of anaerobic conditions in the intestine. Based on in vitro data, it has been suggested that the intestine in the fed state produces lactate under aerobic conditions (Hanson \& Parsons, 1976), even though this has been questioned as a possible artefact due to anaesthesia and surgical manipulation of the bowel (Kimura et al., 1988). During a metabolic challenge, such as an oral glucose load, the intestine has been shown to produce lactate under aerobic conditions in man (Bjorkman et al., 1990). These findings fit well with our notion of aerobic conditions in the control group despite a small net lactate production. In the OA group there was a large increase in arterial lactate concentrations and a corresponding slightly lesser increase in portal venous lactate concentrations. As there was a net mesenteric lactate uptake we conclude that the source of lactate production was not the intestinal vascular bed. In patients with ALI due to inflammation, net lactate production across the lung has been described by several authors (De Backer et al., 1997; Kellum et al., 1997). 
In ${ }^{3} \mathrm{H}$-OA-exposed animals, intestinal tissue was stained for fat and histologically examined (data not shown), but no gross evidence of inflammation such as tissue oedema or neutrophil accumulation and extravasation could be found.

A limitation of our study is the fact that animals in the OA group were given additional fluids and adrenaline during the induction of OA lung injury, as both adrenaline and volume status might affect intestinal haemodynamics and oxygenation. Adrenaline in doses corresponding to those used in our study has been reported to increase both mucosal tissue oxygenation and microvascular haemoglobin oxygen saturation (Salak et al., 2001). However, the circulatory and metabolic effects of adrenaline are short lived (Gilman et al., 1990), and coupled to increases in $\mathrm{HR}$ and $\mathrm{CO}$. As both groups were comparable in $\mathrm{HR}, \mathrm{MAP}$ and $\mathrm{CO}$ at $120 \mathrm{~min}$ (90 min after completion of OA infusion) we suggest that any remaining effect of adrenaline on intestinal haemodynamics and oxygenation at this time-point is unlikely. Extra fluids were given to the OA group to compensate for the expected pulmonary capillary leakage, using CVP as a measure of preload. As global haemodynamics remained stable and were comparable in both groups at $120 \mathrm{~min}$, we believe that the fluid given actually compensated for extravasation of blood volume.

The current study demonstrated that OA infusion induced a severe lung injury. In the control group there were no changes in the equivalent parameters. In both groups there were a sustained decrease in MAP, CO and portal venous blood flow to levels that were approximately $15 \%$ lower than the initial levels. As these effects were also present in the control group, we suggest that these alterations were mainly caused by addition of PEEP and possibly time-related effects of anaesthesia and surgical preparation. There were minimal and clinically insignificant changes in haemodynamic parameters during the late phase of the study period in the OA group.

To conclude, OA given intravenously does not seem to cause intestinal injury, even though it is distributed to extrapulmonary tissues, albeit in small amounts to the intestines. With this knowledge at hand we conclude that the OA lung injury model is suitable for studies on intestinal effects of different treatment modalities during mechanical ventilation of ALI.

\section{Acknowledgments}

We thank Prof. Gunilla Olivecrona, Prof. Hans-Ulrich Rothen and Dr Rickard Palmkvist for valuable exchange of ideas and assistance. This work was supported by grants from the Medical Faculty, Umeå University and the Tore Nilsson Foundation, Stockholm, Sweden. This work was performed at the Experimental Laboratory, Department of Surgical and Perioperative Science, Umeå University, Umeå, Sweden.

\section{References}

Baker PL, Kuenzig MC, Peltier LF. Experimental fat embolism in dogs. J Trauma (1969); 9: 577-586.
Bjorkman O, Eriksson LS, Nyberg B, Wahren J. Gut exchange of glucose and lactate in basal state and after oral glucose ingestion in postoperative patients. Diabetes (1990); 39: 747-751.

Claesson J, Lehtipalo S, Winso O. Do lung recruitment maneuvers decrease gastric mucosal perfusion? Intensive Care Med (2003); 29: 1314-1321.

De Backer D, Creteur J, Zhang H, Norrenberg M, Vincent JL. Lactate production by the lungs in acute lung injury. Am J Respir Crit Care Med (1997); 156: 1099-1104.

Derks CM, Jacobovitz-Derks D. Embolic pneumopathy induced by oleic acid. A systematic morphologic study. Am J Pathol (1977); 87: 143-158.

Doig CJ, Sutherland LR, Sandham JD, Fick GH, Verhoef M, Meddings JB. Increased intestinal permeability is associated with the development of multiple organ dysfunction syndrome in critically ill ICU patients. Am J Respir Crit Care Med (1998); 158: 444-451.

Dreyfuss D, Saumon G. From ventilator-induced lung injury to multiple organ dysfunction? Intensive Care Med (1998); 24: 102-104.

Gilman A, Rall T, Nies A, Taylor PE. Goodman and Gilman's The Pharmacological Basis of Therapeutics, 8th edn (1990). Pergamon Press, New York.

Goeransson G, Olivecrona T. The metabolism of fatty acids in the rat. II. Oleic acid. Acta Physiol Scand (1965); 63: 121-127.

Grotjohan HP, van der Heijde RM, Wagenvoort CA, Wagenvoort N, Versprille A. Pulmonary vasoconstriction in oleic acid induced lung injury. A morphometric study. Int J Exp Pathol (1993); 74: 347-355.

Guery BP, Welsh DA, Viget NB, Robriquet L, Fialdes P, Mason CM, Beaucaire G, Bagby GJ, Neviere R. Ventilation-induced lung injury is associated with an increase in gut permeability. Shock (2003); 19 559-563.

Gullo A, Berlot G. Ingredients of organ dysfunction or failure. World J Surg (1996); 20: 430-436.

Hansard SL. Residual organ blood volume of cattle, sheep and swine. Proc Soc Exp Biol Med (1956); 91: 31-34.

Hanson PJ, Parsons DS. The utilization of glucose and production of lactate by in vitro preparations of rat small intestine: effects of vascular perfusion. J Physiol (1976); 255: 775-795.

Imai Y, Parodo J, Kajikawa O, de Perrot M, Fischer S, Edwards V, Cutz E, Liu M, Keshavjee S, Martin TR, Marshall JC, Ranieri VM, Slutsky AS. Injurious mechanical ventilation and end-organ epithelial cell apoptosis and organ dysfunction in an experimental model of acute respiratory distress syndrome. JAMA (2003); 289: 2104-2112.

Kellum JA, Kramer DJ, Mankad S, Bellomo R, Lee K, Pinsky MR. Release of lactate by the lung in acute lung injury. Adv Exp Med Biol (1997); 411: 281-285.

Kimura RE, LaPine TR, Gooch WM, III. Portal venous and aortic glucose and lactate changes in a chronically catheterized rat. Pediatr Res (1988); 23: $235-240$.

Kloot TE, Blanch L, Melynne Youngblood A, Weinert C, Adams AB, Marini JJ, Shapiro RS, Nahum A. Recruitment maneuvers in three experimental models of acute lung injury. Effect on lung volume and gas exchange. Am J Respir Crit Care Med (2000); 161: 1485-1494.

Lehtipalo S, Biber B, Frojse R, Arnerlov C, Johansson G, Winso O. Effects of positive end-expiratory pressure on intestinal circulation during graded mesenteric artery occlusion. Acta Anaesthesiol Scand (2001); 45: 875-884.

Lehtipalo S, Biber B, Frojse R, Arnerlov C, Johansson G, Winso O. Effects of dopexamine and positive end-expiratory pressure on intestinal blood flow and oxygenation: the perfusion pressure perspective. Chest (2003); 124: 688-698.

Lim SC, Adams AB, Simonson DA, Dries DJ, Broccard AF, Hotchkiss JR, Marini JJ. Transient hemodynamic effects of recruitment maneuvers in three experimental models of acute lung injury. Crit Care Med (2004); 32: $2378-2384$. 
Mainous MR, Ertel W, Chaudry IH, Deitch EA. The gut: a cytokinegenerating organ in systemic inflammation? Shock (1995); 4: 193-199.

Neumann P, Hedenstierna G. Ventilation-perfusion distributions in different porcine lung injury models. Acta Anaesthesiol Scand (2001); 45: 78-86.

Nieuwenhuijzen GA, Goris RJ. The gut: the 'motor' of multiple organ dysfunction syndrome? Curr Opin Clin Nutr Metab Care (1999); 2: 399404 .

Pelosi P, Goldner M, McKibben A, Adams A, Eccher G, Caironi P, Losappio S, Gattinoni L, Marini JJ. Recruitment and derecruitment during acute respiratory failure: an experimental study. Am J Respir Crit Care Med (2001); 164: 122-130.

Plotz FB, Slutsky AS, van Vught AJ, Heijnen CJ. Ventilator-induced lung injury and multiple system organ failure: a critical review of facts and hypotheses. Intensive Care Med (2004); 30: 1865-1872.
Rosenthal C, Caronia C, Quinn C, Lugo N, Sagy M. A comparison among animal models of acute lung injury. Crit Care Med (1998); 26: 912916.

Sakka SG, Reinhart K, Meier-Hellmann A. Comparison of pulmonary artery and arterial thermodilution cardiac output in critically ill patients. Intensive Care Med (1999); 25: 843-846.

Salak N, Pajk W, Knotzer H, Hofstotter H, Schwarz B, Mayr A, Labeck B, Kafka R, Ulmer H, Mutz N, Hasibeder W. Effects of epinephrine on intestinal oxygen supply and mucosal tissue oxygen tension in pigs. Crit Care Med (2001); 29: 367-373.

Winso O, Biber B, Gustavsson B, Holm C, Milsom I, Niemand D. Portal blood flow in man during graded positive end-expiratory pressure ventilation. Intensive Care Med (1986); 12: 80-85. 